Buletin Ilmiah Math. Stat. dan Terapannya (Bimaster)

Volume 08, No. 2 (2019), hal 363 - 370.

\title{
PENGGUNAAN METODE GREEKS BLACK SCHOLES UNTUK ANALISIS SENSITIVITAS HARGA OPSI BELI EROPA
}

\author{
Nana Pratiwi, Evy Sulistianingsih , Nurfitri Imro'ah
}

\begin{abstract}
INTISARI
Investor yang melakukan usaha bisnis seperti investasi dengan aset dasar saham mempunyai risiko yang dapat menyebabkan kerugian. Dengan demikian investor perlu melakukan lindung nilai seperti opsi. Namun dengan menggunakan opsi investor masih mengadapi risiko, sehingga diperlukan manajemen risiko harga opsi. Metode Greeks merupakan alat penting dalam manajemen risiko. Greeks merupakan lima huruf yunani dan derivatif dari model Black-Scholes yang digunakan untuk mengetahui sensitivitas yang dimiliki opsi. Hasil analisis sensitivitas penelitian ini yaitu diperoleh nilai delta yang mempunyai sensitivitas paling tinggi ketika harga saham awal lebih besar dari harga pelaksanaan dan semakin dekat dengan waktu jatuh tempo (ITM). Nilai gamma yang diperoleh mempunyai sensitivitas paling tinggi ketika harga saham awal berada disekitar harga pelaksanaan dan semakin dekat dengan waktu jatuh tempo (ATM). Nilai Theta yang diperoleh mempunyai sensitivitas paling tinggi ketika harga saham awal berada disekitar harga pelaksanaan dan semakin dekat dengan waktu jatuh tempo (ATM). Nilai vega yang diperoleh mempunyai sensitivitas paling tinggi ketika harga saham awal berada disekitar harga pelaksanaan dan semakin jauh dengan waktu jatuh tempo (ATM). Nilai Rho yang diperoleh mempunyai sensitivitas paling tinggi ketika harga saham awal saham lebih besar dari harga pelaksanaan dan semakin jauh dengan waktu jatuh tempo (ITM).
\end{abstract}

Kata Kunci : Opsi beli tipe Eropa, Model Black-Scholes, Metode Greeks, Analisis sensitivitas

\section{PENDAHULUAN}

Investasi adalah komitmen untuk menanamkan sejumlah dana pada saat ini dengan tujuan memperoleh keuntungan di masa datang [1]. Dunia keuangan mengenal adanya pasar keuangan yang dapat dijadikan investasi baik investasi pada pasar uang (money market) yaitu investasi pada rill aset (tanah, bangunan, dan pertambangan) maupun pasar modal (capital market) yaitu investasi pada finansial aset (saham, obligasi, emas) [1]. Investasi tentunya mempunyai risiko yang dapat menyebabkan kerugian, sehingga investor berupaya untuk melindungi nilai dari aset dasar yang mana dalam penelitian ini adalah saham. Dalam melakukan lindung nilai saham investor dapat membeli sebuah kontrak opsi .

Opsi merupakan suatu kontrak yang memberikan hak (bukan kewajiban) kepada pemegang opsi untuk membeli atau menjual suatu aset tertentu dengan harga dan waktu tertentu [1]. Berdasarkan jenis hak yang diberikan opsi dibedakan menjadi opsi beli dan opsi jual. Opsi beli adalah jenis opsi yang memberikan hak kepada pemegang opsi untuk membeli suatu aset tertentu pada harga dan waktu tertentu [2]. Sedangkan berdasarkan waktu penggunaannya opsi dibedakan menjadi opsi tipe Eropa dan Amerika. Opsi tipe Eropa digunakan hanya pada tanggal jatuh tempo saja [3]. Penentuan harga opsi beli tipe Eropa dapat menggunakan model Black-Scholes dengan asumsi harga saham berdistribusi Lognormal dan return berdistribusi Normal [4]. Saham tidak membayarkan dividen (pembagian keuntungan saham), volatilitas konstan, serta suku bunga konstan.

Untuk memanajemen risiko dari investasi opsi dengan aset dasar saham investor dapat menganalisis sensitivitas harga opsi [4]. Analisis sensitivitas merupakan teknik untuk memanajemen risiko. Dengan menganalisis sensitivitas harga opsi, dapat diketahui akibat yang akan terjadi dari perubahan-perubahan indikator didalam opsi yang dapat diantisipasi. 
Analisis sensitivitas dilakukan dengan menggunakan metode Greeks pada model Black-Scholes. Metode Greeks merupakan alat penting dalam memanajemen risiko untuk mengetahui sensitivitas pada harga opsi. Metode Greeks mempunyai lima nilai (delta, gamma, theta, vega, dan rho), kelima nilai tersebut dapat menganalisis empat indikator yang mempengaruhi harga opsi. Sehingga tujuan dari penelitian ini untuk menganalisis sensitivitas harga opsi menggunakan metode Greeks Black-Scholes.

Penelitian ini dimulai dengan mencari data harga saham pada http://www.finance.yahoo.com. kemudian menghitung return saham, kemudian menguji normalitas return, jika return berdistribusi Normal maka dilanjutkan menginput nilai dari indikator-indikator dalam opsi yaitu harga saham awal, harga pelaksanaan, waktu jatuh tempo, tingkat suku bunga bebas risiko yang diperoleh dari http://www.fxstreet.com/fundamental/interest-rates-table/, dan menghitung volatilitas return. Setelah didapat nilai dari indikator yang diperlukan selanjutnya menghitung harga opsi, kemudian menghitung nilai sensitivitas harga opsi beli Eropa (delta, gamma, theta, vega, dan rho), setelah diperoleh nilai sensitivitas harga opsi maka dilakukan interpretasi hasil analisis.

\section{RETURN HARGA SAHAM}

Hasil atau akibat yang diperoleh dari investasi yang dilakukan disebut dengan (return). Nilai return dapat negatif dan juga dapat positif, artinya tingkat keuntungan atau pengembalian yang diperoleh sesuai dengan kondisi rill dari aset yang menjadi investasi yang mana dalam penelitian ini adalah saham[5]. Return harga saham dihitung menggunakan persamaan sebagai berikut[6]:

$$
R_{t}=\ln \left(\frac{S_{t}}{S_{t-1}}\right)
$$

dengan $R_{t}$ menyatakan return harga saham pada saat $t, S_{t}$ menyatakan harga saham pada saat $t$, dan $S_{t-1}$ menyatakan harga saham pada saat $t-1$ [7].

\section{VOLATILITAS HARGA SAHAM}

Volatilitas adalah ukuran perubahan harga saham dapat naik atau turun (berfluktuasi) dengan cepat. Volatitas menggambarkan perubahan dan pergerakan harga saham dimasa lalu (data historis). Jika semua indikator lain dianggap tetap, semakin besar volatilitas maka peluang harga saham semakin besar mengalami perubahan, hal ini disebabkan pada periode waktu jatuh tempo dapat terdeviasi jauh keatas[4]. Volatilitas tahunan harga saham dihitung menggunakan persamaan sebagai berikut:

$$
\sigma=\sqrt{k \times S^{2}}
$$

dengan $k$ menyatakan banyaknya data return harga saham dan $S^{2}$ menyatakan variansi dari return harga saham. Untuk menghitung variansi dapat digunakan persamaan sebagai berikut:

$$
S^{2}=\frac{\sum_{t=1}^{k}\left(R_{t}{ }^{2}\right)-\sum_{t=1}^{k}\left(R_{t}\right)^{2}}{k(k-1)}
$$

dengan $S^{2}$ menyatakan variansi, $k$ menyatakan banyaknya data return harga saham, $R_{t}$ menyatakan return harga saham periode $t$.

\section{UJI NORMALITAS KOLMOGOROV-SMIRNOV}

Tujuan dari uji ini adalah untuk mengetahui apakah data yang diambil adalah data yang terdistribusi Normal. Misalkan Misalkan $Y_{1}, Y_{2} \ldots Y_{n}$ adalah sampel random berukuran $n$ dari suatu populasi dengan fungsi distribusi $F(y)$. Andaikan $F_{0}(y)$ adalah suatu fungsi distribusi tertentu dan akan diuji [8]:

$$
\begin{aligned}
& H_{0}: F(y)=F_{0}(y) \\
& H_{1}: F(y) \neq F_{0}(y)
\end{aligned}
$$


Uji Kolmogorov-Smirnov menggunakan statistik uji:

$$
T=\sup _{-\infty<y<\infty}\left|F_{n}(y)-F_{0}(y)\right|
$$

Kesimpulan yang diambil adalah menolak $H_{0}$ jika nilai $T>T_{n, \alpha} . T_{n, \sigma}$ nilai kritik dari statistik $T$.

\section{MODEL BLACK-SCHOLES}

Model Black-Scholes diperkenalkan oleh Fischer Black dan Myron Scholes pada tahun 1973. Model Black-Scholes terbatas karena hanya dapat digunakan pada penentuan harga opsi tipe Eropa (European Option) yang djalankan pada waktu jatuh tempo (expiration date) saja. Dalam suatu opsi terdapat nilai yang merupakan fungsi dari berbagai macam indikator, dinotasikan dengan $V(S ; t ; \sigma ; K ; T ; r)$, dengan $S$ adalah harga saham (underlying asset), $t$ adalah waktu atau periode, $K$ adalah harga pelaksanaan (strike price), $T$ adalah waktu jatuh tempo opsi (expiration date), $\sigma$ adalah nilai dari volatilitas harga saham, dan $r$ adalah suku bunga bebas risiko [9]. Model Black Scholes mengasumsikan bahwa harga saham menyebar Lognormal untuk memenuhi imbal hasil aset dasar menyebar Normal [4]. Model Black-Scholes dengan indikator waktu $\tau=T-t$ dinyatakan sebagai berikut [10]:

$$
C=S_{0} N\left(d_{1}\right)-K e^{-r \tau} N\left(d_{2}\right)
$$

dimana $C$ adalah nilai opsi beli, $S_{0}$ adalah harga saham awal, $N\left(d_{1}\right)$ adalah fungsi distribusi kumulatif normal standar dari $d_{1}$, dan $N\left(d_{2}\right)$ adalah fungsi distribusi kumulatif normal standar dari $d_{2}$. dengan:

$$
\begin{aligned}
& d_{1}=\frac{\ln \left(\frac{S_{0}}{K}\right)+\left(r+\frac{\sigma^{2}}{2}\right) \tau}{\sigma \sqrt{\tau}} \\
& d_{2}=\frac{\ln \left(\frac{S_{0}}{K}\right)+\left(r-\frac{\sigma^{2}}{2}\right) \tau}{\sigma \sqrt{\tau}}
\end{aligned}
$$

dengan $\tau$ menyatakan selisih waktu $t$ hingga waktu jatuh tempo $T$.

\section{METODE GREEKS}

Metode Greeks dapat digunakan untuk memanajemen risiko di pasar modal khususnya opsi. Hal ini dikarenakan setiap unsur Greeks menganalisis indikator yang berbeda terhadap risiko dalam opsi [11]. Setiap nilai Greeks (delta, gamma, theta, vega, dan rho) menganalisis perubahan harga opsi akibat perubahan indikator dari opsi (harga saham, waktu, volatilitas dan suku bunga).

\section{Delta $(\Delta)$}

Delta merupakan sensitivitas harga opsi terhadap perubahan harga aset dasar yang mana dalam penelitian ini adalah saham [11]. Persamaan delta dinotasikan dengan [12]:

$$
\Delta=\frac{\partial C}{\partial S_{0}}=\frac{\partial\left(S_{0} N\left(d_{1}\right)-K e^{-r \tau} N\left(d_{2}\right)\right)}{\partial S_{0}}=N\left(d_{1}\right)
$$

\section{2. $\operatorname{Gamma}(\Gamma)$}

Gamma didefinisikan tingkat perubahan delta terhadap perubahan harga aset dasar yang mana dalam penelitian ini adalah saham [11]. Persamaan gamma dinotasikan dengan [12]:

$$
\Gamma=\frac{\partial \Delta}{\partial S_{0}}=\frac{\partial\left(N\left(d_{1}\right)\right)}{\partial S_{0}}=\frac{1}{S_{0} \sigma \sqrt{2 \pi \tau}} e^{-\frac{d_{1}^{2}}{2}}
$$

\section{Theta $(\Theta)$}

Delta merupakan sensitivitas harga opsi terhadap perubahan waktu [11]. Persamaan theta dinotasikan dengan [12]: 


\section{4. $\operatorname{Vega}(v)$}

$$
\Theta=\frac{\partial C}{\partial t}=-\frac{\partial C}{\partial \tau}=-\frac{\partial\left(S_{0} N\left(d_{1}\right)-K e^{-r \tau} N\left(d_{2}\right)\right)}{\partial \tau}=-\frac{S_{0} \sigma}{2 \tau^{1 / 2}} N^{\prime}\left(d_{1}\right)-r K e^{-r \tau} N\left(d_{2}\right)
$$

Vega merupakan sensitivitas harga opsi terhadap perubahan nilai volatilitas harga saham [11]. Persamaan vega dinotasikan dengan [12]:

$$
v=\frac{\partial C}{\partial \sigma}=\frac{\partial\left(S_{0} N\left(d_{1}\right)-K e^{-r \tau} N\left(d_{2}\right)\right)}{(\sigma)}=S_{0} \sqrt{\tau} N^{\prime}\left(d_{1}\right)
$$

\section{5. $\operatorname{Rho}(\rho)$}

Rho merupakan sensitivitas harga opsi terhadap perubahan suku bunga [11]. Persamaan vega dinotasikan dengan [12]:

$$
\rho=\frac{\partial C}{\partial r}=\frac{\partial\left(S_{0} N\left(d_{1}\right)-K e^{-r \tau} N\left(d_{2}\right)\right)}{\partial r}=K \tau e^{-r \tau} N\left(d_{2}\right)
$$

\section{STUDI KASUS DAN PEMBAHASAN}

Penelitian ini menggunakan simulasi pada data penutupan harga saham Coca Cola Company (KO) pada september 2017 hingga september 2018 yang berjumlah 252 data. Data yang digunakan merupakan data sekunder yang diperoleh melalui http://www.finance.yahoo.com/. Kemudian dilakukan perhitungan return harga saham. Berikut statistik deskriptif return harga saham Coca Cola Company:

Tabel 1 Statistik Deskriptif Data Return Saham Coca-Cola Company

\begin{tabular}{cc}
\hline Karakteristik & Nilai \\
\hline Jumlah Data Return & 251 \\
Minimum & $-0,04017$ \\
Maksimum & 0,01963 \\
Skewness & $-0,73400$ \\
Kurtosis & 2,35600 \\
\hline
\end{tabular}

Pada Tabel 1 dapat dilihat bahwa data return harga saham Coca-Cola Company (KO) berjumlah 251 data dengan nilai minimum -0,04017 dan nilai maksimum 0,01963 kemudian data return condong kekiri dengan nilai skewness $-0,73400$. Kemudian selanjutnya melakukan uji normalitas return menggunakan uji Kolmogorof-Smirnov dengan kriteria menolak $H_{0}$ jika nilai $p$-value $>(\alpha)$ dapat dilihat pada Tabel 2 sebagai berikut:

Tabel 2 Uji Normalitas Return Harga Saham

\begin{tabular}{cc}
\hline Karakteristik & Nilai \\
\hline Sampel Observation & 251 \\
Asymp. Sig. (2-tailed) & $\mathbf{0 , 3 1 7}$ \\
\hline
\end{tabular}

Hasil pada Tabel 2 menunjukkan bahwa nilai $p$-value $=0,317 ; p$-value $>0,05(\alpha)$ maka data return berdistribusi Normal. Selanjutnya menghitung harga opsi beli tipe Eropa menggunakan Persamaan (5). dengan menentukan terlebih dahulu indikator yang digunakan dalam menghitung harga opsi, yaitu harga saham awal $\left(S_{0}\right)$ ditentukan berdasarkan data penutupan harga saham (close price) perusahaan Coca Cola Company (KO) periode 25 september 2017 sampai dengan 24 september 2018 mulai dari harga saham terendah $\$ 41$ hingga harga saham tertinggi $\$ 48$. Kemudian menentukan harga pelaksanaan $(K)$ sebesar $\$ 44,5$, menentukan tingkat suku bunga bebas risiko $(r)$ yang ditetapkan oleh Bank Central Amerika yaitu sebesar $2,25 \%$, selanjutnya menentukan waktu jatuh tempo $(T)$. Pada penelitian ini, waktu jatuh tempo $(T)$ yang digunakan sebanyak 3 bulan atau jika dijadikan tahun nilainya adalah 0,25 dan dibagi menjadi tiga bulan waktu jatuh tempo. Kemudian selanjutnya nilai volatilitas diperoleh berdasarkan Persamaan (2) yaitu sebesar 0,1340. Untuk lebih jelas nilai opsi dapat dilihat pada Tabel 3 sebagai berikut: 
Tabel 3 Perhitungan Harga Opsi Beli Tipe Eropa

\begin{tabular}{cccc}
\hline $\begin{array}{c}\text { Harga Saham } \\
\text { Awal }(\$)\end{array}$ & $\begin{array}{c}\text { Opsi Beli 1 Bulan } \\
\text { Sebelum Jatuh Tempo } \\
(\tau=0,08)\end{array}$ & $\begin{array}{c}\text { Opsi Beli 2 Bulan } \\
\text { Sebelum Jatuh Tempo } \\
(\tau=0,17)\end{array}$ & $\begin{array}{c}\text { Opsi Beli 3 Bulan } \\
\text { Sebelum Jatuh Tempo } \\
(\tau=0,25)\end{array}$ \\
\hline 41 & 0,01166 & 0,08039 & 0,18156 \\
42 & 0,05541 & 0,20133 & 0,36058 \\
43 & 0,19021 & 0,43129 & 0,64628 \\
44 & 0,49437 & 0,80675 & 1,05888 \\
45 & 1,02081 & 1,34452 & 1,60528 \\
46 & 1,75743 & 2,03534 & 2,27771 \\
47 & 2,64000 & 2,84941 & 3,05696 \\
48 & 3,59834 & 3,74907 & 3,91819 \\
\hline
\end{tabular}

Dapat dilihat pada Tabel 3 hasil perhitungan harga opsi beli tipe Eropa bahwa harga opsi semakin meningkat apabila harga aset dasar (harga saham) semakin meningkat.

\section{Menentukan Sensitivitas Harga Opsi Beli Eropa}

\section{Nilai Delta $(\Delta)$}

Nilai delta diperoleh dari Persamaan (8). Apabila hasil perhitungan semakin tinggi maka menunjukkan bahwa nilai delta semakin sensitif (nilai delta yang paling tinggi adalah yang paling sensitif). Untuk lebih jelas dapat dilihat pada Tabel 4 sebagai berikut:

Tabel 4 Nilai Delta pada Opsi Beli tipe Eropa

\begin{tabular}{cccc}
\hline $\begin{array}{c}\text { Harga Saham } \\
\text { Awal }(\$)\end{array}$ & $\begin{array}{c}\text { Nilai Delta 1 Bulan } \\
\text { Sebelum Jatuh Tempo } \\
(\tau=0,08)\end{array}$ & $\begin{array}{c}\text { Nilai Delta 2 Bulan } \\
\text { Sebelum Jatuh Tempo } \\
(\tau=0,17)\end{array}$ & $\begin{array}{c}\text { Nilai Delta 3 Bulan } \\
\text { Sebelum Jatuh Tempo } \\
(\tau=0,25)\end{array}$ \\
\hline 41 & 0,02024 & 0,08065 & 0,13468 \\
42 & 0,07692 & 0,16841 & 0,22811 \\
43 & 0,20664 & 0,29786 & 0,34676 \\
44 & 0,41132 & 0,45598 & 0,47961 \\
45 & 0,63926 & 0,6179265 & 0,61183 \\
46 & 0,82235 & 0,75852 & 0,72972 \\
47 & 0,93056 & 0,86312 & 0,82453 \\
48 & $\mathbf{0 , 9 7 8 5 1}$ & 0,93044 & 0,89377 \\
\hline
\end{tabular}

Pada Tabel 4 hasil perhitungan menunjukkan bahwa nilai delta yang memiliki sensitivitas paling tinggi adalah ketika harga saham awal lebih besar dari harga pelaksanaan dan mendekati waktu jatuh tempo [13]. Nilai delta semakin tinggi pada saat opsi in the money (ITM) [4].

\section{Nilai $\operatorname{Gamma}(\Gamma)$}

Nilai gamma diperoleh dari Persamaan (9). Apabila hasil perhitungan semakin tinggi maka menunjukkan bahwa nilai gamma semakin sensitif (nilai gamma yang paling tinggi adalah yang paling sensitif). Untuk lebih jelas dapat dilihat pada Tabel 5 sebagai berikut:

Tabel 5 Nilai Gamma pada Opsi Beli tip e Eropa

\begin{tabular}{cccc}
\hline $\begin{array}{c}\text { Harga Saham } \\
\text { awal }(\$)\end{array}$ & $\begin{array}{c}\text { Nilai Gamma 1 Bulan } \\
\text { Sebelum Jatuh Tempo } \\
(\tau=0,08)\end{array}$ & $\begin{array}{c}\text { Nilai Gamma 2 Bulan } \\
\text { Sebelum Jatuh Tempo } \\
(\tau=0,17)\end{array}$ & $\begin{array}{c}\text { Nilai Gamma 3 Bulan } \\
\text { Sebelum Jatuh Tempo } \\
(\tau=0,25)\end{array}$ \\
\hline 41 & 0,03084 & 0,06667 & 0,078886 \\
42 & 0,08879 & 0,10944 & 0,107376 \\
43 & 0,17157 & 0,14728 & 0,128091 \\
44 & $\mathbf{0 , 2 2 8 5 1}$ & 0,16468 & 0,135110 \\
45 & 0,21501 & 0,15488 & 0,127048 \\
46 & 0,14620 & 0,12392 & 0,107306 \\
47 & 0,07337 & 0,08522 & 0,081974 \\
48 & 0,02769 & 0,05087 & 0,057001 \\
\hline
\end{tabular}


Pada Tabel 5 hasil perhitungan menunjukkan bahwa nilai gamma yang memiliki sensitivitas paling tinggi adalah ketika harga saham awal berada disekitar harga pelaksanaan dan semakin dekat dengan waktu jatuh tempo [13]. Nilai gamma semakin besar pada saat opsi at the money (ATM) [4].

\section{Nilai Theta $(\Theta)$}

Nilai theta diperoleh dari Persamaan (10). Nilai theta menggambarkan penyusutan nilai opsi sejalan dengan waktu disebut dengan time decay, dan nilai theta yang paling kecil merupakan nilai theta yang paling sensitif .Untuk lebih jelas dapat dilihat pada Tabel 6 sebagai berikut:

Tabel 6 Nilai Theta pada Opsi Beli tipe Eropa

\begin{tabular}{cccc}
\hline $\begin{array}{c}\text { Harga Saham } \\
\text { Awal (\$) }\end{array}$ & $\begin{array}{c}\text { Nilai Theta 1 Bulan } \\
\text { Sebelum Jatuh Tempo } \\
(\tau=0,08)\end{array}$ & $\begin{array}{c}\text { Nilai Theta 2 Bulan } \\
\text { Sebelum Jatuh Tempo } \\
(\tau=0,17)\end{array}$ & $\begin{array}{c}\text { Nilai Theta 3 Bulan } \\
\text { Sebelum Jatuh Tempo } \\
(\tau=0,25)\end{array}$ \\
\hline 41 & $-0,48430$ & $-1,07984$ & $-1,31200$ \\
42 & $-1,47924$ & $-1,88976$ & $-1,90986$ \\
43 & $-3,04693$ & $-2,72611$ & $-2,44963$ \\
44 & $-4,37225$ & $-3,29881$ & $-2,80196$ \\
45 & $-\mathbf{4 , 5 3 7 5 5}$ & $-3,41426$ & $-2,89568$ \\
46 & $-3,59220$ & $-3,09588$ & $-2,74480$ \\
47 & $-2,38135$ & $-2,54060$ & $-2,43067$ \\
48 & $-1,54943$ & $-1,97388$ & $-2,05750$ \\
\hline
\end{tabular}

Pada Tabel 6 hasil perhitungan menunjukkan bahwa nilai theta yang memiliki sensitivitas paling tinggi adalah ketika harga saham awal berada disekitar harga pelaksanaan dan semakin dekat dengan waktu jatuh tempo[13]. Nilai theta semakin besar pada saat opsi at the money (ATM) [4].

\section{Nilai Vega $(v)$}

Nilai vega diperoleh dari Persamaan (11). Apabila hasil perhitungan semakin tinggi maka menunjukkan bahwa nilai vega semakin sensitif (nilai vega yang paling tinggi adalah yang paling sensitif). Untuk lebih jelas dapat dilihat pada Tabel 7 sebagai berikut:

Tabel 7 Nilai Vega pada Opsi Beli tipe Eropa

\begin{tabular}{cccc}
\hline $\begin{array}{c}\text { Harga Saham } \\
\text { Awal }(\$)\end{array}$ & $\begin{array}{c}\text { Nilai Vega 1 Bulan } \\
\text { Sebelum Jatuh Tempo } \\
(\tau=0,08)\end{array}$ & $\begin{array}{c}\text { Nilai Vega 2 Bulan } \\
\text { Sebelum Jatuh Tempo } \\
(\tau=0,25)\end{array}$ & $\begin{array}{c}\text { Nilai Vega 3 Bulan } \\
\text { Sebelum Jatuh Tempo } \\
(\tau=0,25)\end{array}$ \\
\hline 41 & 0,57914 & 2,50424 & 4,44476 \\
42 & 1,75003 & 4,31394 & 6,34880 \\
43 & 3,54445 & 6,08532 & 7,93848 \\
44 & 4,94278 & 7,12431 & 8,76748 \\
45 & 4,86459 & 7,00829 & 8,62335 \\
46 & 3,45658 & 5,85901 & 7,61072 \\
47 & 1,81080 & 4,20655 & 6,06950 \\
48 & 0,713045 & 2,61886 & 4,40204 \\
\hline
\end{tabular}

Pada Tabel 7 hasil perhitungan menunjukkan bahwa nilai vega yang memiliki sensitivitas paling tinggi adalah ketika harga saham awal berada disekitar harga pelaksanaan dan semakin jauh dengan waktu jatuh tempo [13]. Nilai vega semakin besar pada saat opsi at the money (ATM) [4].

\section{Nilai Rho $(\rho)$}

Nilai rho diperoleh dari Persamaan (12). Apabila hasil perhitungan semakin tinggi maka menunjukkan bahwa nilai rho semakin sensitif (nilai rho yang paling tinggi adalah yang paling sensitif). Untuk lebih jelas dapat dilihat pada Tabel 8 sebagai berikut: 
Tabel 8 Nilai rho pada Opsi Beli tipe Eropa

\begin{tabular}{cccc}
\hline $\begin{array}{c}\text { Harga Saham } \\
\text { Awal }(\$)\end{array}$ & $\begin{array}{c}\text { Nilai Rho 1 Bulan } \\
\text { Sebelum Jatuh Tempo }\end{array}$ & $\begin{array}{c}\text { Nilai Rho 2 Bulan } \\
\text { Sebelum Jatuh Tempo }\end{array}$ & $\begin{array}{c}\text { Nilai Rho 3 Bulan } \\
\text { Sebelum Jatuh Tempo }\end{array}$ \\
\hline 41 & 0,06820 & 0,53770 & 1,33505 \\
42 & 0,26460 & 1,14530 & 2,30503 \\
43 & 0,72460 & 2,06276 & 3,56615 \\
44 & 1,46697 & 3,20941 & 5,01099 \\
45 & 2,31216 & 4,41028 & 6,48181 \\
46 & 3,00590 & 5,47612 & 7,82235 \\
47 & 3,42472 & 6,28626 & 8,92402 \\
48 & 3,61420 & 6,81872 & $\mathbf{9 , 7 4 5 7 0}$ \\
\hline
\end{tabular}

Pada Tabel 8 hasil perhitungan menunjukkan bahwa nilai rho yang memiliki sensitivitas paling tinggi adalah ketika harga saham awal lebih besar dari harga pelaksanaan dan semakin jauh dari waktu jatuh tempo [13]. Nilai rho semakin besar pada saat opsi in the money (ITM) [4]

\section{KESIMPULAN}

Menganalisis sensitivitas harga opsi merupakan upaya untuk lindung nilai (hedging) dari aset yang mendasari opsi (saham). Dengan melakukan analisis sensitivitas maka dapat diketahui akibat yang mungkin terjadi dari perubahan-perubahan indikator didalam opsi dan dapat di antisipasi sebelum terjadi. Berdasarkan hasil penelitian pada pembahasan dengan simulasi saham Coca Cola Company (KO) dapat disimpulkan bahwa delta menunjukkan sensitivitas paling tinggi terjadi ketika harga saham awal lebih besar dari harga pelaksanaan dan semakin dekat dengan waktu jatuh tempo (ITM), Gamma menunjukkan sensitivitas paling tinggi ketika harga saham awal berada disekitar harga pelaksanaan dan mendekati waktu jatuh tempo (ATM), Theta menunjukkan sensitivitas paling tinggi terjadi ketika harga saham awal berada disekitar harga pelaksanaan dan semakin dekat dengan waktu jatuh tempo (ATM), Vega menunjukkan sensitivitas paling tinggi terjadi ketika harga saham awal berada disekitar harga pelaksanaan dan semakin jauh dengan waktu jatuh tempo (ATM), Rho menunjukkan sensitivitas paling tinggi terjadi ketika harga saham awal semakin besar dari harga pelaksanaan dan semakin jauh dengan waktu jatuh tempo (ITM).

\section{DAFTAR PUSTAKA}

[1]. Halim A. Analisis Investasi. Ed ke-2. Jakarta: Salemba Empat. 2005.

[2]. Higham DJ. An Introduction To Financial Option Valuation, Mathematics, Stochastics and Computation. United Kingdom: Cambridge University Press. 45-120; 2004.

[3]. Luenberger DG. Investment Science. New York: Oxford University Press. 1998.

[4]. Sunaryo T. Manajemen Risiko Finansial. Jakarta: Selemba Empat. 2007.

[5]. Hull JC. Options Futures and Other Derivatives, $8^{\text {nd }}$ Editions. Prentice Hall. New jersey. 2006.

[6]. Widyawati, Satyahadewi N, Sulistianingsih E. Penggunaan Model Black-Scholes untuk Penentuan Harga Opsi Jual Tipe Eropa. Buletin Ilmiah Math, Stat, dan Terapannya (Bimaster). 2013; Vol. 02. No.1: 13-20.

[7]. Nadia S, Sulistianingsih E, Imro'ah N. Penentuan Harga Opsi Tipe Eropa Dengan Metode Binomial. Buletin Ilmiah Math, Stat, dan Terapannya (Bimaster). 2018; Vol.7. No.2:127-134.

[8]. Siegel S. Nonparametric Statistic: Fpr The Behavioral Sciences. McGraw-Hill Book Company Inc, New York;1956.

[9]. Qiu Y \& Lorenz J. A Non-Linear Black-Scholes Equation. International. Jurnal Business Performance and Supply Chain Modelling. 2009; Vol.1. No.1: 33-40.

[10].Yuliandi TD, Devianto D \& Yozza H. Perbandingan Metode Black-Scholes dan Simulasi Monte Carlo Dalam Penentuan Harga Opsi Eropa. Jurnal Matematika UNAND. 2015; Vol.5. No.1:7-16.

[11].Chen H.Y, Lee CF, and Shih W. Derivatives and Applications of Greek Letters-Review and Integration. USA: Rutgers University. 2008.

[12].Yu X and Xie X. On Derivations of Black-Scholes Greeks Letters, Research Journal of Finance an Accounting. 2013; Vol.4. No.6:80-85. 
[13].Nataran DN, Dharmawan K \& Nilakusumawati DPE. Analisis Sensitivitas Harga Opsi Menggunakan Metode Greek Black-Scholes. E-Jurnal Matematika. 2018; Vol.7. No.2:148-156

\begin{tabular}{|c|c|}
\hline NANA PRATIWI & $\begin{array}{l}\text { : Jurusan Matematika FMIPA UNTAN, Pontianak, } \\
\text { nanapratiwi@ student.untan.ac.id }\end{array}$ \\
\hline EVY SULISTIANINGSIH & $\begin{array}{l}\text { : Jurusan Matematika FMIPA UNTAN, Pontianak, } \\
\text { evysulistianingsih@ @ath.untan.ac.id }\end{array}$ \\
\hline NURFITRI & $\begin{array}{l}\text { : Jurusan Matematika FMIPA UNTAN, Pontianak, } \\
\text { nurfitriimroah18@gmail.com }\end{array}$ \\
\hline
\end{tabular}

